\title{
A new species of Pterodectes Robin, 1877 (Proctophyllodidae: Pterodectinae) from the pale-breasted thrush, Turdus leucomelas (Passeriformes: Turdidae)
}

\author{
FÁBIO A. HERNANDES ${ }^{1} \&$ MICHEL P. VALIM ${ }^{2}$ \\ 1- Programa de Pós-Graduação em Biologia Animal - Depto. Zoologia e Botânica. Instituto de Biociências, \\ Letras e Ciências Exatas - IBILCE. Universidade Estadual Paulista - UNESP, campus de São José do Rio \\ Preto;Rua Cristóvão Colombo, 2265, Jardim Nazareth, São José do Rio Preto, SP, Brazil, 15054-000; Email: \\ fabio_akashi@yahoo.com.br \\ 2 - Depto. Parasitologia. Universidade Federal de Minas Gerais - UFMG; Av. Presidente Antônio Carlos, \\ 6627, Pampulha, Belo Horizonte, MG, Brazil, 31270-901: Email: mpvalim@ hotmail.com
}

\begin{abstract}
A new species of feather mite, Pterodectes fissuratus sp. n., is described from the pale-breasted thrush, Turdus leucomelas Veillot (Passeriformes: Turdidae), in Brazil. This species is easily distinguished by having numerous well-pronounced lacunae and a longitudinal median furrow on prodorsal and hysteronotal shields in both sexes.
\end{abstract}

Key words: Astigmata, feather mite, Analgoidea, systematics, Brazil

\section{INTRODUCTION}

Feather mites (Astigmata: Analgoidea, Freyanoidea, Pterolichoidea), a vast group of permanent inhabitants of bird plumage, currently include over 2,400 described species (Mironov 2003). However, this number likely represents only a minute fraction of existing species (Gaud \& Atyeo 1996). In the present paper, we describe a new feather mite species, Pterodectes fissuratus sp. n. (Analgoidea: Proctophyllodidae: Pterodectinae), collected from the pale-breasted thrush, Turdus leucomelas Veillot (Passeriformes: Turdidae). The feather mite subfamily Pterodectinae includes about 110 species (Park \& Atyeo 1971) and is one of two major subfamilies of Proctophyllodidae. Representatives of this family mainly inhabit the ventral surfaces of flight and covert feathers of the wings (Dabert \& Mironov 1999). Mites of the genus Pterodectes are known to occur on ten families of the order Passeriformes: Corvidae, Emberizidae, Fringillidae, Furnariidae, 